Article

\title{
Asymmetric Impact of Financial Intermediary Development in Low- and High-Income Countries
}

\author{
Chi-Chun Yang ${ }^{1}$ and Ya-Kai Chang ${ }^{2, *}$ \\ 1 Department of Accounting, National Taiwan University, No.1, Sec. 4, Roosevelt Rd., Taipei City 106, Taiwan; \\ kendax0613@gmail.com \\ 2 Department of Finance, Chung Yuan Christian University, No. 200, Zhongbei Rd., Zhongli Dist., \\ Taoyuan City 320, Taiwan \\ * Correspondence: ykchang@cycu.edu.tw
}

Received: 13 June 2020; Accepted: 20 July 2020; Published: 24 July 2020

check for updates

\begin{abstract}
This study uses the quantile regression method developed by Koenker and Bassett (1978) to examine the asymmetric effect of financial intermediary development on economic growth in low- and high-income countries. A three-sector neoclassical growth model composed of a representative family sector, production sector, and the financial intermediary sector is constructed, and the equilibrium solutions determine the variables employed in the empirical model. The empirical results reveal an asymmetric relationship between financial intermediary development and economic growth. Financial intermediary development is the main driving force of economic growth for high-income countries only, not for low-income countries. Overall, this study suggests that countries should not develop financial intermediaries indiscriminately in the pursuit of economic expansion, especially for low-income countries. Our empirical findings have important policy implications for regulators who are especially concerned about countries' sustainable economic growth.
\end{abstract}

Keywords: three-sector endogenous growth model; quantile regression; financial intermediation; human capital; economic growth; sustainability

\section{Introduction}

Past literature suggests that there exists a positive relationship between financial intermediary development and economic growth. However, another interesting issue is whether the development of financial institutions always has a positive influence on a country's economic growth. Existing theoretical and empirical literature has yet to provide a clear answer on this issue, due to lack of considering different income levels in different countries (i.e., low-income countries vs. high-income countries), while examining the effect of financial intermediary development. Therefore, our study attempts to fill this gap in the existing literature by applying a two-stage process. In the first stage, we try to find potential determinants which significantly affect economic growth by constructing a three-sector (i.e., including the representative family, production, and financial intermediary sectors) endogenous growth model based on the Romer [1] model. In the second stage, after determining the factors influencing economic growth, we then use quantile regression (hereafter QR), introduced by Koenker and Basset [2], to examine the asymmetric effect of financial intermediary development on economic growth; that is, how financial intermediary development affects the different quantiles of the economic growth distribution.

Studies had not focused on analyzing the impact of endogenous variables on economic growth until Romer [1] constructed a growth model with endogenous technological change. Romer [1] argued that both technological change (i.e., knowledge accumulation) and the accumulation of human capital (i.e., education level) would induce sustainable long-term economic growth. Romer [1] further 
pointed out that the interaction and complementary relationship between technological progress and human capital plays the critical role in the creation, acceleration, and sustainability of economic growth. Specifically, the utilization of more human capital in research results in a greater amount of production of new designs and accumulation of knowledge, which increases worker productivity and thus boosts economic growth. Based on Romer's model, researchers have further augmented their work by examining the relationship between financial system development and economic growth, such as Fu et al. [3], Levine [4], and Odedokun [5]. Fu et al. [3] showed that financial deregulation stimulates economic growth through capital accumulation using Chinese provincial data. Levine [4] demonstrated that the development of financial markets significantly influences the rate of growth and the accumulation of capital. Similarly, Odedokun [5] reported that the activity of financial intermediation promotes a country's economic growth.

On the other hand, an increasing body of the literature investigates financial intermediary development across countries. For example, previous studies reveal the impact of financial intermediary development on economic growth, such as those of Cheng and Hou [6], Levine et al. [7], and Mhadhbi et al. [8]. Cheng and Hou [6] examined the impact of financial intermediation and non-intermediation services on economic growth for eight Organization for Economic Cooperation and Development (OECD) countries. The empirical results revealed that non-intermediation financial services hinder Austria's and France's long-term economic growth, whereas non-intermediation services accelerate long-run economic growth in Korea. Levine et al. [7] suggested that financial intermediary development impacts positively on economic growth; moreover, the differences in accounting systems and legal origins among countries significantly account for different degrees of financial development. Similarly, Mhadhbi et al. [8] investigated the relationship between financial intermediary development and economic growth for forty developing countries during the period 1970-2012. They found that there is a causal relationship between financial intermediary development and economic growth in twenty-five countries.

Furthermore, prior literature also shows how the various firm and country characteristic affect financial intermediary development, such as studies by Beck et al. [9] and Demirgüç-Kunt and Levine [10]. For example, Beck et al. [9] found that small companies benefit from financial intermediary development, which in turn encourages economic growth. Demirgüç-Kunt and Levine [10] examined 48 countries at various income levels and concluded that countries with higher income tend to have higher ratios of financial development (e.g., bank assets to gross domestic product (hereafter GDP), M2 money supply (hereafter M2) to GDP, and quasi-money to GDP) than countries with lower income do. In addition, previous studies indicate that the effect of bank liquidity risk on the relationship between financial intermediary development and economic growth after a financial crisis, such as those by Bencivenga and Smith [11] and Greenwood and Smith [12]. Both Bencivenga and Smith [11] and Greenwood and Smith [12] reported that liquidity shocks affect individual savings, which subsequently change the GDP of a country. Finally, researchers have started investigating the impact of government policies on long-run growth through technological advances, such as Jones and Kim [13] and Aghion et al. [14]. Jones and Kim [13] found that top income inequality has a negative relationship with the technological innovation, whereas Aghion et al. [14] showed that this relationship goes the other way.

We construct a three-sector endogenous growth model comprising the representative family, production, and financial intermediary variables. Human capital is represented by higher education or the hourly earnings ratio. The interest spread, net interest margin, or the ratio of central bank assets to GDP (excluding the ratio of bank assets to GDP, M2 to GDP, and quasi-money to GDP) serves as a proxy variable for the degree of financial development. The variables employed in the QR model are determined by the basis of equilibrium solutions from the endogenous growth model. Overall, the empirical results indicate that financial intermediary development has more influence on economic growth in high-income countries, whereas human capital and capital accumulation are the driving forces of growth in low-income countries. This study thus clarifies the source of economic growth for countries at different levels of economic development. Overall, our analysis and results 
have important policy implications for policy makers in terms of reforming the regulation for countries' sustainable economic development.

The remainder of this article is organized as follows: Section 2 presents the methodology, Section 3 describes the empirical results, and Section 4 discusses the conclusions.

\section{Methodology}

\subsection{Three-Sector Endogenous Growth Model}

The model used follows the concepts outlined in the neoclassical growth model. In general, the construction of the system enables manufacturers to obtain capital for production to earn profits and enables the household unit to provide services and receive payment.

\subsubsection{Representative Family}

This model assumes that typical household characteristics are represented by a constant elasticity of substitution utility function. That is, household units in each phase have defined labor provisions, and there exists a trade-off between work time and leisure time. Moreover, a representative family is an infinitely long-lived economic entity. The utility function at the beginning is as follows:

$$
\sum_{t=0}^{\infty}(1+\beta)^{-t}\left\{\phi \ln c(t)+(1-\phi) \ln \left[1-\hat{n}_{P}(t)-\hat{n}_{B}(t)\right]\right\} \phi(t),
$$

where $c(t)$ is the household real consumption during period $t ; 1-\hat{n}_{P}(t)-\hat{n}_{B}(t)$ is the leisure at time $t$ with $\hat{n}_{P}(t)$ and $\hat{n}_{B}(t)$ representing the provision of the household labor units for production of goods and banking activities, respectively; $\beta$ is the rate of time preference; $\phi$ and $1-\phi$ are the correlation coefficients for consumption and recreation, respectively; $\phi(t)$ is the population at time $t$ with $v$ growth rate, i.e., $\phi(t)=\phi(0)(1+v)^{t}$.

The household's payments for consumption and investment expenditures with income come from the net earnings from supplying labor and the rents of supplying capital. That is, the household's intertemporal budget constraint is as follows:

$$
c(t)+\hat{D}(t+1)-\hat{D}(t) \leq w_{P}(t) \hat{n}_{P}(t)+w_{B}(t) \hat{n}_{B}(t)+r_{D} \hat{D}(t),
$$

where $w_{P}(t)$ and $w_{P}(t)$ are the real wage of labor for production of goods and banking activities, respectively; $r_{D}$ is the interest rate of deposit and $r_{D} \hat{D}(t)$ is the interest between $t-1$ and $t$. Note that $\hat{D}(t+1)-\hat{D}(t)$ is the household's deposit at time $t$. On the other hand, the household's available time constraint is as follows:

$$
\hat{n}_{p}(t)+\hat{n}_{B}(t) \leq 1,
$$

where $\hat{n}_{B}(t), \hat{n}_{B}(t)$ have been defined by Equation (1).

\subsubsection{Production Sector}

Romer [1] introduced human capital to the production function with the main purpose of clarifying whether economic growth results from increases in population or from improvements in human capital. The production output of a manufacturer is modeled by the Cobb-Douglas function. Vendors integrate their assets (fixed assets) to borrow from banks (loans) to create capital, $K(t)$. Therefore, the production equation is as follows:

$$
Y(t)=[K(t)]^{\theta_{1}}\left[N_{P}(t)\right]^{\theta_{2}} \sum_{m=1}^{\infty} x_{m}^{1-\theta_{1}-\theta_{2}}
$$

where $Y(t)$ is the total output, $K(t)$ is the total capital investment of the vendors; $N_{P}(t)$ is the total labor input of the manufacturer; $\theta_{1}$ and $\theta_{2}$ are the shares of capital and labor; $\sum_{m=1}^{\infty} x_{m}$ is the 
total factor inputs of other relevant manufacturers. The variable $N_{P}(t)$ is specifically defined as $N_{P}(t)=N_{P, A}(t)+N_{P, Y}(t)$, where $N_{P, A}(t)$ represents the total human capital investment in research (or the advancement for manufacturing technology) by manufacturers, and $N_{P, Y}(t)$ is the sum of human capital input in production by manufacturers. Intuitively, the production function, the capital investment, and the labor are rewritten in per-capita terms as $(t)=Y(t) / \phi(t), k(t)=K(t) / \phi(t)$, and $n(t)=N(t) / \phi(t)$, respectively. In this system, because the total capital of a manufacturer includes its own capital and borrowings from banks, $K(t)$, is set equal to the constant elasticity of substitution (CES) function of the total manufacturer's own capital (or the retained earnings) $\operatorname{RE}(t)$ and the total loans $L(t)$ :

$$
K(t)=\psi(t)\left\{\alpha[\operatorname{RE}(t)]^{-\rho}+(1-\alpha)[L(t)]^{-\rho}\right\},
$$

where $\alpha$ and $1-\alpha$ are the correlation coefficients for the manufacturer's own capital and loans, respectively; $\psi(t)$ is the efficiency parameter; $\rho$ is the parameter between equity capital and borrowing, where the elasticity of substitution between equity capital and borrowing can be expressed as $(1+\rho)^{-1}$.

\subsubsection{Financial Intermediation Sector}

Assuming that the main intermediary activity of financial institutions (in this instance, banks) is the lending of household deposits to manufacturers, the basic production equation of banks used in this study follows Goodfriend and McCallum [15]:

$$
\hat{L}(t)=\xi(t)[(1-\gamma) D(t)]^{\eta_{1}}\left[N_{B}(t)\right]^{\eta_{2}} \sum_{m=1}^{\infty} x_{m}^{1-\eta_{1}-\eta_{2}} .
$$

In Equation (6), $\hat{L}(t)$ is the sum of all loans; $D(t)$ is the sum of all deposits; $N_{B}(t)$ is the household labor units for banking activities; $\gamma$ is the necessary reserve rate of banks; $\eta_{1}$ and $\eta_{2}$ are the shares of deposit and labor; $\sum_{m=1}^{\infty} x_{m}$ is the sum of other relevant factors of bank output; $\xi(t)$ is the exogenous efficiency parameter for banks. Moreover, $N_{B}(t)$ is defined as $N_{B}(t)=N_{B, A}(t)+N_{B, Y}(t)$, where $N_{B, A}(t)$ and $N_{B, Y}(t)$ are the total human capital investments used in innovation and traditional lending businesses.

\subsubsection{Equilibrium}

To establish the equilibrium of the model, the following steps are taken. First, solve the maximization problem of the production sector. Assuming that the cost of labor and the cost of the loan are $\left\{w_{P}(t), r_{L}(t)\right\}_{t=0}^{\infty}$, then the maximization problem of the production sector can be solved, thus yielding $K^{F}(t), N_{P}(t)$, and $L(t)$ :

$$
\max _{\left\{K(t+1), N_{P}(t), L(t)\right\}_{\}^{\infty}=0}^{\infty}} \sum_{t=0}^{\infty} p(t) Y(t)-\mathrm{PC}\left[t ; N_{P}(t),:(t)\right]-\operatorname{IE}[t ; K(t+1)],
$$

where $\mathrm{PC}(t)$ is the cost of production including the cost of labor and the cost of the loan; $\operatorname{IE}(t)$ is the investment expenditure, i.e.,

$$
\begin{gathered}
\mathrm{PC}\left[t ; N_{P}(t),:(t)\right]=w_{P}(t) N_{P}(t)+r_{L}(t) L(t), \\
\mathrm{IE}[t ; K(t+1)]=K(t+1)-(1-\delta) K(t),
\end{gathered}
$$

where $\delta$ is the rate of depreciation. The profit of the production sector, like Equation (7), is subjected to the following condition:

$$
\begin{gathered}
Y(t)=[K(t)]^{\theta_{1}}\left[N_{P}(t)\right]^{\theta_{2}} \sum_{m=1}^{\infty} x_{m}^{1-\theta_{1}-\theta_{2}}, \\
K(t)=\psi(t)\left\{\alpha[\operatorname{RE}(t)]^{-\rho}+(1-\alpha)[L(t)]^{-\rho}\right\}
\end{gathered}
$$




$$
N_{P}(t)=N_{P, A}(t)+N_{P, Y}(t) .
$$

Second, determine the maximization problem of the financial intermediation sector. Assuming that the cost of labor, the cost of capital, and the deposit interest rate are $\left\{w_{B}(t), r_{L}(t), r_{D}(t)\right\}_{t=0}^{\infty}$, then the maximization problem of the financial intermediation sector is represented by $N_{B}(t)$ :

$$
\max _{\left\{N_{B}(t), D(t)\right\}_{t=0}^{\infty}} \sum_{t=0}^{\infty} r_{L}(t) \hat{L}(t)-r_{D}(t) D(t)-w_{B}(t) N_{B}(t)
$$

which is subjected to

$$
\begin{gathered}
\hat{L}(t)=\xi(t)[(1-\gamma) D(t)]^{\eta_{1}}\left[N_{B}(t)\right]^{\eta_{2}} \sum_{m=1}^{\infty} x_{m}^{1-\eta_{1}-\eta_{2}}, \\
N_{B}(t)=N_{B, A}(t)+N_{B, Y}(t) .
\end{gathered}
$$

Third, after solving the maximization problems of the production sector and financial intermediation sectors, the results substitute into the maximization utility function of the household.

$$
\max _{\left\{\hat{n}_{P}(t), \hat{n}_{B}(t), \hat{D}(t)\right\}_{t=0}^{\infty}} \sum_{t=0}^{\infty}\left(\frac{1+v}{1+\beta}\right)^{t}\left\{\phi \ln c(t)+(1-\phi) \ln \left[1-\hat{n}_{P}(t)-\hat{n}_{B}(t)\right]\right\},
$$

which is subjected to

$$
\begin{gathered}
c(t)+\hat{D}(t+1)-\hat{D}(t) \leq w_{P}(t) \hat{n}_{P}(t)+w_{B}(t) \hat{n}_{B}(t)+r_{D} \hat{D}(t), \\
\hat{n}_{p}(t)+\hat{n}_{B}(t) \leq 1 .
\end{gathered}
$$

Fourth, the market-clearing conditions are outlined as follows:

$$
L(t)=\hat{L}(t), \quad D(t)=\hat{D}(t), \quad H(t)=\hat{H}(t),
$$

At the point of equilibrium, the debit and credit sides of the capital market and labor market must be clear, and equilibrium prices are represented as $r_{L}(t), r_{D}(t), w_{P}(t)$, and $w_{B}(t)$.

\subsection{Empirical Analysis}

As shown in the three-sector endogenous growth model, the equilibrium growth path is related to human capital (e.g., education), capital stock, the development of financial intermediaries, and the company's efficiency factors. Therefore, regression analysis is performed to investigate the relationship between economic growth and these factors. In addition to the traditional ordinary least squares (OLS) estimation, in particular, this study uses QR, because the OLS method observes only the "average" effect of financial institutions toward economic growth and fails to indicate whether financial development is a key factor engendering economic growth in countries at various levels of economic development. Another drawback of OLS is its sensitivity to extreme sample points in the data. Consequently, Mello and Perrelli [16] built the QR model as a new regression estimation technique. Using an endogenous growth model and QR, this study explains how financial development asymmetrically engenders economic growth in different countries.

\subsubsection{Introduction of Quantile Regression}

This study uses QR to generate precise results instead of OLS regression. Because QR parameters depend on the distribution of past samples, a more accurate estimate of the distribution of dependent variables can be derived according to the marginal effects of independent variables. The QR method facilitates differentiating economic growth from financial growth among countries. This method can further explain whether high-income countries, as well as low-income countries, experience the same 
effect. Normally, the OLS method can only determine whether financial activities affect the economic growth of a country, but it cannot explain the reason for the importance of the variable of financial activities in countries with different degrees of economic development. However, once independent variables affect parameters other than conditional mean values in dependent variables, the result may be extremely biased (Koenker and Bassett, [2]). Therefore, in contrast to the OLS method, QR provides a flexible framework for modeling characteristics of the conditional distribution of dependent variables.

When examining the relationship between the conditional distribution of dependent and independent variables, researchers sometimes apply the OLS method to subsets of the data produced by separating the complete data set into different percentiles of the dependent variables. However, because not all of the data are being used for each OLS estimate, the traditional OLS method results in the problem of sample selection bias. In contrast to the OLS method, the QR method uses all of the data for each estimate. The QR method therefore avoids the problem of sample selection bias, which presents in the OLS regression analysis.

\subsubsection{Empirical Model Setting}

Based on the aforementioned three-sector endogenous growth model, this study determines that GDP growth is affected by factors such as human capital, capital stock, the development of financial intermediaries, and companies' efficiency. Hence, the following function is derived by setting GDP growth as the dependent variable and the other factors as independent variables:

$$
\operatorname{GDP}^{\text {growth }}(t)=f[N(t), K(t), F(t), Z(t)] .
$$

Each variable is that $Y(t)$ is the sum of the output; $N(t)$ is the human capital; $K(t)$ is the total capital; $F(t)$ is the financial development variables; $Z(t)$ is other factors affecting the total output. Other factors that affect the total output, such as Equations (4) and (6) and variable $\sum_{m=1}^{\infty} x_{m}$ are explained in Table 1 and the next section.

\subsection{Data Description and Variables Selection}

Data in this study are derived from international financial statistics; the annual budgets of 15 countries from 2000 January to 2012 December are analyzed. The GDP ranking of the countries is presented in Table 2.

Table 1. Symbols and definitions of dependent and independent variables.

\begin{tabular}{|c|c|c|}
\hline Variable Name & Symbol & Definition \\
\hline \multicolumn{3}{|r|}{ Dependent variable } \\
\hline \multicolumn{3}{|r|}{$\begin{array}{l}\frac{\operatorname{gdppc}(\mathrm{t})-\mathrm{gdppc}(\mathrm{t}-1)}{\mathrm{gdppc}(\mathrm{t}-1)}, \text { where gdppc is the country's GDP divided by the } \\
\text { total number of people in the country in a given year } t .\end{array}$} \\
\hline \multicolumn{3}{|c|}{ Independent variables (about household) } \\
\hline Consumer price index & cpi & $\begin{array}{l}\text { A measure that examines the weighted average of prices of a basket of } \\
\text { consumer goods and services. }\end{array}$ \\
\hline Higher educated rate & edu & total number educated above senior high school divided by all citizens \\
\hline \multicolumn{3}{|c|}{ Independent variables (about firm) } \\
\hline Capital & cpl & \\
\hline industrial production & ip & \\
\hline Producer price index & ppi & \\
\hline Wage hourly earnings & whe & \\
\hline \multicolumn{3}{|c|}{ Independent variables (about the scale of financial institution) } \\
\hline Liquid liabilities to GDP & llgdp & $\frac{\text { Currency }+ \text { Current liabilities of banks }}{\text { GDP }}$ \\
\hline Financial system's deposits to GDP & fdgdp & $\frac{\text { Deposits of financial intermediaries }}{\text { GDP }}$ \\
\hline Bank deposits to GDP & bdgdp & $\frac{\text { Deposits of commercial banks }}{\text { GDP }}$ \\
\hline Private credit to GDP & pcrdbofgdp & $\begin{array}{c}\text { the private sector's deposits in the commercial banks and other } \\
\text { intermediaries per GDP }\end{array}$ \\
\hline
\end{tabular}


Table 1. Cont.

\begin{tabular}{|c|c|c|}
\hline Variable Name & Symbol & Definition \\
\hline \multicolumn{3}{|c|}{ Independent variables (about the efficiency and stability of financial institution) } \\
\hline Interest spread & is & Lending rate-Deposit rates \\
\hline Central bank assets to GDP & cbagdp & $\frac{\text { Central bank assets }}{\text { GDP }}$ \\
\hline Deposit money banks' assets to GDP & dbagdp & Deposit money banks assets \\
\hline & & $\begin{array}{c}\text { GDP } \\
\text { Other financial assets }\end{array}$ \\
\hline Other financial assets to GDP & ofagdp & $\frac{\text { Other tinanclal assets }}{\text { GDP }}$ \\
\hline Deposit money vs. central bank assets & dbacba & $\frac{\text { Deposit money bank assets }}{\text { Deposit money }+ \text { Centralbank assets }}$ \\
\hline Net interest margin & netintmargin & Net interest \\
\hline Overhead cost & overhead & $\frac{\text { Total cost }}{\text { Banks assets }}$ \\
\hline Return on assets & roa & \\
\hline Return on equity & roe & \\
\hline Bank z-score & zscore $\quad \mathrm{Tl}$ & $\begin{array}{l}\text { The ratio of return on assets plus capital-asset-The ratio to the standard } \\
\text { deviation of return on assets. }\end{array}$ \\
\hline \multicolumn{3}{|c|}{ Dependent variable (About financial market) } \\
\hline Stock market capitalization to GDP & stmktcap & $\frac{\text { The value of stock market }}{\text { GDP }}$ \\
\hline Bond Market capitalization to GDP & pubond & $\frac{\text { The value of bond market }}{\text { GDP }}$ \\
\hline Stock market turnover ratio & stturnover & The turnover of stock market \\
\hline \multicolumn{3}{|c|}{ Dependent variable (the index of financial integration) } \\
\hline International debt issues to GDP & intldebt & $\frac{\text { The value of stock market }}{\text { GDP }}$ \\
\hline Offshore deposits to domestic deposits & offdep & $\frac{\text { Offshore bank deposits }}{\text { Domestic bank deposits }}$ \\
\hline Remittance inflows to GDP & remit & $\frac{\text { Remittance inflows }}{\mathrm{GDP}}$ \\
\hline
\end{tabular}

Note that the information on this table is obtained from international financial statistics.

Table 2. GDP analysis of the countries.

\begin{tabular}{cccc}
\hline Number & Country Name & Abbreviation & Income Classification \\
\hline 1 & Taiwan & TWN & high \\
2 & Japan & JPN & high \\
3 & Korea & KOR & high \\
4 & United & GBR & high \\
5 & Kingdom & USA & high \\
6 & United States & BLZ & medium high \\
7 & Brazil & MYS & medium high \\
8 & Malaysia & RUS & medium high \\
9 & Russia & CHN & medium low \\
10 & China & IND & medium low \\
11 & India & PHL & medium low \\
12 & Philippines & THA & medium low \\
13 & Thailand & VNM & low \\
14 & Vietnam & KHM & low \\
15 & Cambodia & MMR & low \\
\hline
\end{tabular}

Note that the information on this table is obtained from the United Nations Economic Commission.

The income classifications are high, medium high, medium, medium low, and low. By ranking these countries, this study can observe whether the effect of each variable differs between countries at different stages of development. The definitions and symbols of all variables are presented in Table 2 . We follow Baldwin and Forslid [17] and Beck et al. [18] to select our independent variables for each of the three sectors to perform the empirical analyses. The selected independent variables are as follows:

1. For the household sector, this study selects consumer price index (CPI), labor supply, employment, and population growth as variables (Baldwin and Forslid, [2]). Specifically, education is used to determine whether economic development results from labor capital quality (According to the United Nations Economic Commission, gross enrolment ratio in tertiary education is defined as "a nation's total enrollment in a tertiary level of education, regardless of age, expressed as a percentage of the population to tertiary level of education") or from population growth. 
2. For the production sector, capital industrial production, producer price index (PPI), and wage rate are selected as the independent variables (Baldwin and Forslid, [17]).

3. For the financial intermediary sector, in addition to interest spread, numerous indices including scale, efficiency, capital market momentum, and international banking are chosen (Beck et al., [18]):

- To examine the scale of a financial system, this study first calculates the ratio of financial sector liquid liabilities to GDP, which can be used to evaluate the growth of financial institutions according to their liquid liability holdings; ratios of financial system deposits to GDP and bank deposits to GDP are also employed. The ratio of private credit by deposit money at banks and other financial institutions to GDP (pcrdbofgdp) is the proportion of private deposits in commercial banks to GDP, indicating that the more the deposits that people place in banks, the faster national wealth grows (Beck et al., [19,20]).

- To examine the scale, efficiency, and stability of a financial system, the following independent variables are evaluated: central bank assets to GDP, deposit money banks' assets to GDP, other financial institutions' assets to GDP, and deposit money versus central bank assets. Furthermore, an efficiency index is calculated using net interest margin and overhead cost; a higher net interest margin indicates that a bank uses its assets adequately, whereas a higher overhead cost indicates that a bank does not use its assets efficiently. Finally, the profit earning ability of a bank is examined using the return on assets and return on equity. The stability variable of a bank is represented by a z-score, which is calculated from the following equation:

$$
Z=1.2 T_{1}+1.4 T_{2}+3.3 T_{3}+0.6 T_{4}+0.999 T_{5}
$$

where $T_{1}$ is the working capital; $T_{2}$ is the retained earnings; $T_{3}$ is the earnings before interest and taxes; $T_{4}$ is the market value of equity; $T_{5}$ is sales. Here, the $z$-score is a measure of the banking sector health of a country; the higher the ratio is, the more robust the banking sector is.

- To determine whether the ability of a company to self-finance can affect economic growth, the scale of the stock and bond markets and the stock market turnover ratio are considered.

- Finally, the ratio of international debt issues to GDP is included to evaluate the overseas debt of a nation in relation to its GDP. The ratio of offshore deposits to domestic deposits and the ratio of remittance inflows to GDP are also valuable indices.

\section{Empirical Results}

Table 3 presents a statistical analysis of variables in the model. Median and median absolute deviation evaluate the position and deviation of each variable. As shown in the table, variables such as education (edu) and CPI (cpi) have outliers on the median, mean, and standard deviation analysis.

Table 3. Statistical analysis of each variable.

\begin{tabular}{cccccc}
\hline & Mean & S.D. & Q1 & Median & Q3 \\
\hline gdpr & 0.1046 & 0.1029 & 0.0479 & 0.0929 & 0.1565 \\
edu & 39.5417 & 27.3560 & 13.0000 & 32.0000 & 62.5000 \\
llgdp & 0.7588 & 0.4888 & 0.4564 & 0.6390 & 1.0244 \\
fdgdp & 0.6964 & 0.4879 & 0.4068 & 0.5751 & 0.9550 \\
bdgdp & 0.6859 & 0.4881 & 0.4068 & 0.5751 & 0.9550 \\
cbagdp & 0.0490 & 0.0499 & 0.0172 & 0.0259 & 0.0582 \\
dbacba & 0.8995 & 0.1554 & 0.8904 & 0.9530 & 0.9836 \\
netintmargin & 0.0357 & 0.0199 & 0.0218 & 0.0291 & 0.0418 \\
overhead & 0.0281 & 0.0186 & 0.0148 & 0.0222 & 0.0400 \\
roa & 0.0112 & 0.0122 & 0.0040 & 0.0093 & 0.0145 \\
roe & 0.0949 & 0.1247 & 0.0516 & 0.1027 & 0.1444 \\
zscore & 7.7531 & 5.9334 & 3.8571 & 5.6263 & 9.3997 \\
cpi & 125.3000 & 52.2310 & 101.7000 & 108.8000 & 121.2000 \\
\hline
\end{tabular}




\subsection{Ordinary Least Squares (OLS) Model}

Table 4 shows the estimation results when we do our analysis by using the OLS method. For the efficiency and asset structure of financial intermediation, the empirical results indicate that the coefficient of the efficiency of assets usage (roa) is 3.2909, and the t-value is 3.82 , the coefficient of the asset structure of deposit money (dbacba) is 0.3227 , and the $t$-value is 2.49 . That is, there is a positive relationship between the efficiency and asset structure of a financial intermediary and the country's economic growth, consistent with Fu et al. [3], Levin et al. [4], and Odedokun [5]. In addition, the coefficient of CPI (cpi) is 0.0015 , and the t-value is 6.85; that is, CPI has a significant positive impact on economic growth. Furthermore, education level (edu) has a significant negative impact on economic growth; its coefficient is -0.0008 , and the $t-v a l u e$ is -2.08 . However, this empirical result deviates from common knowledge, suggesting that there is a negative relationship between education level and economic growth.

Table 4. Analysis results from the ordinary least squares (OLS) model.

\begin{tabular}{ccccc}
\hline Variable & Coefficient & s.e. & t-Value & Pr $>|\mathbf{t}|$ \\
\hline Intercept & $-0.3289^{* * *}$ & 0.1198 & -2.75 & 0.0071 \\
edu & $-0.0008^{* *}$ & 0.0004 & -2.08 & 0.0395 \\
llgdp & -0.1477 & 0.1031 & -1.43 & 0.1549 \\
fdgdp & 0.0433 & 0.2389 & 0.18 & 0.8566 \\
bdgdp & 0.0839 & 0.2610 & 0.32 & 0.7486 \\
cbagdp & -0.2275 & 0.3202 & -0.71 & 0.4791 \\
dbacba & $0.3227^{* *}$ & 0.1295 & 2.49 & 0.0143 \\
netintmargin & 0.3070 & 1.1742 & 0.26 & 0.7943 \\
overhead & 0.6971 & 0.9699 & 0.72 & 0.4739 \\
roa & $3.2909^{* * *}$ & 0.8604 & 3.82 & 0.0002 \\
roe & -0.1141 & 0.0774 & -1.47 & 0.1434 \\
zscore & -0.0003 & 0.0017 & -0.18 & 0.8553 \\
cpi & $0.0015^{* * *}$ & 0.0002 & 6.85 & $<0.0001$ \\
Year effects & Yes & & & \\
Obs. & 215 & & & \\
Adjusted R-square & 0.325 & & & \\
\hline$* *$ and *** represent significance at the $5 \%$, and $1 \%$ levels, respectively.
\end{tabular}

\subsection{Quantile Regression (QR) Model}

Table 5 presents the regression results of the QR method at the 50th percentile, which are similar to the estimate from the OLS method. The results indicate that the coefficient of the ratio of deposit money bank assets to total bank assets (dbacba) is 0.2689 and the t-value is 2.05. Therefore, the ratio of deposit money bank assets to total assets of financial institutions is positively related to economic development. These empirical results are consistent with Fu et al. [3], Levin et al. [4], and Odedokun [5]. In addition, Table 5 reveals that the coefficient of education level (edu) is -0.0007 and the $t$-value is -1.85 . The empirical result of education level in $\mathrm{QR}$ is statistically significant and indicates a negative value. That is, education level is negatively related to GDP growth. Again, the empirical result of education level shown here is not considered common knowledge, showing that an increase in education level is positively related to economic growth.

Table 5. Analysis results from quantile regression (QR).

\begin{tabular}{ccccccc}
\hline Variable & Coefficient & s.e. & 95\% Confidence & Limits & t-Value & $\operatorname{Pr}>|\mathbf{t}|$ \\
\hline Intercept & -0.2347 & 0.1439 & -0.5199 & 0.0506 & -1.63 & 0.1059 \\
edu & $-0.0007^{*}$ & 0.0004 & -0.0014 & 0.0000 & -1.85 & 0.0665 \\
llgdp & $-0.1707^{*}$ & 0.1016 & -0.3721 & 0.0307 & -1.68 & 0.0958 \\
fdgdp & 0.1135 & 0.2557 & -0.3936 & 0.6206 & 0.44 & 0.6582 \\
\hline
\end{tabular}


Table 5. Cont.

\begin{tabular}{|c|c|c|c|c|c|c|}
\hline Variable & Coefficient & s.e. & 95\% Confidence & Limits & t-Value & $\operatorname{Pr}>|t|$ \\
\hline bdgdp & 0.0622 & 0.2863 & -0.5054 & 0.6298 & 0.22 & 0.8284 \\
\hline cbagdp & -0.4415 & 0.3190 & -1.0740 & 0.1909 & -1.38 & 0.1692 \\
\hline dbacba & $0.2689^{* *}$ & 0.1313 & 0.0085 & 0.5293 & 2.05 & 0.0431 \\
\hline netintmargin & 0.4569 & 1.2255 & -1.9731 & 2.8868 & 0.37 & 0.7101 \\
\hline overhead & 0.1324 & 1.0325 & -1.9149 & 2.1797 & 0.13 & 0.8982 \\
\hline roa & 1.6101 & 1.4307 & -1.2267 & 4.4469 & 1.13 & 0.2630 \\
\hline roe & 0.0482 & 0.1095 & -0.1689 & 0.2653 & 0.44 & 0.6607 \\
\hline zscore & 0.0001 & 0.0015 & -0.0028 & 0.0030 & 0.07 & 0.9454 \\
\hline cpi & $0.0013^{* * *}$ & 0.0003 & 0.0007 & 0.0019 & 4.21 & 0.0001 \\
\hline Year effects & Yes & & & & & \\
\hline Obs. & 215 & & & & & \\
\hline $\begin{array}{l}\text { Adjusted } \\
R \text {-square }\end{array}$ & 0.242 & & & & & \\
\hline
\end{tabular}

To further examine whether the impact of financial intermediary development and education levels on economic growth have different outcomes on different groups with different income levels, we next focus on the entire conditional distribution of the independent variable (i.e., the GDP growth rate) by figure analysis. Figure 1 presents empirical results, where the shaded bands on the graphs represent 95\% confidence intervals and the curves represent the QR results. According to the GDP growth rate (gdpr) of each country, high-income countries possessing low and stable economic growth have a lower rate of economic growth, whereas low-income countries with fast and volatile economic growth are considered have a higher rate of economic growth. Therefore, high-income countries are in the low-conditional quantile of the GDP growth rate, whereas low-income countries are in the high-conditional quantile of the GDP growth rate.

Our empirical results show that in a high-income country, the more the deposits that are stored in commercial banks (bdgdp) as the proxy for the size of the banking system, the stronger is its economic development. That is, in high-income countries, the development of financial intermediaries has a positive impact on economic growth. Accordingly, high-income countries should encourage the development of financial institutions to promote economic development. The size of the financial intermediaries in a country is relevant because it influences the number and amount of loans banks can lend to companies. By contrast, in low-income countries, the greater the efficiency of assets usage (roa) and the higher the ratio of deposit money bank assets to total bank assets, including deposit money bank assets and central bank assets (dbacba), the stronger is its economic growth. Therefore, low-income countries should focus on improving the efficiency and asset structure of financial intermediation to stimulate economic growth. Finally, for CPI, the impact on economic growth is negative in high-income countries, whereas the impact on economic growth is positive in low-income countries.

Figure 2 shows that education level relates negatively (positively), though not significantly to economic growth, in the low (high) conditional quantile of the GDP growth rate. The reason for this change is that in high-income countries, the GDP growth rate is much slower than that of low-income countries; moreover, when labor quality reaches a certain level, the marginal effect of education on GDP growth is negative. In the low-conditional quantile of the GDP growth rate, the negative slope curve illustrates conditions in high-income countries, but in the high-conditional quantile of the GDP growth rate, the curve depicts conditions in low-income countries. These compelling results explain that for low-income countries, increasing the education level of the populace instead of developing financial institutions is a more effective approach to boost economic growth. 


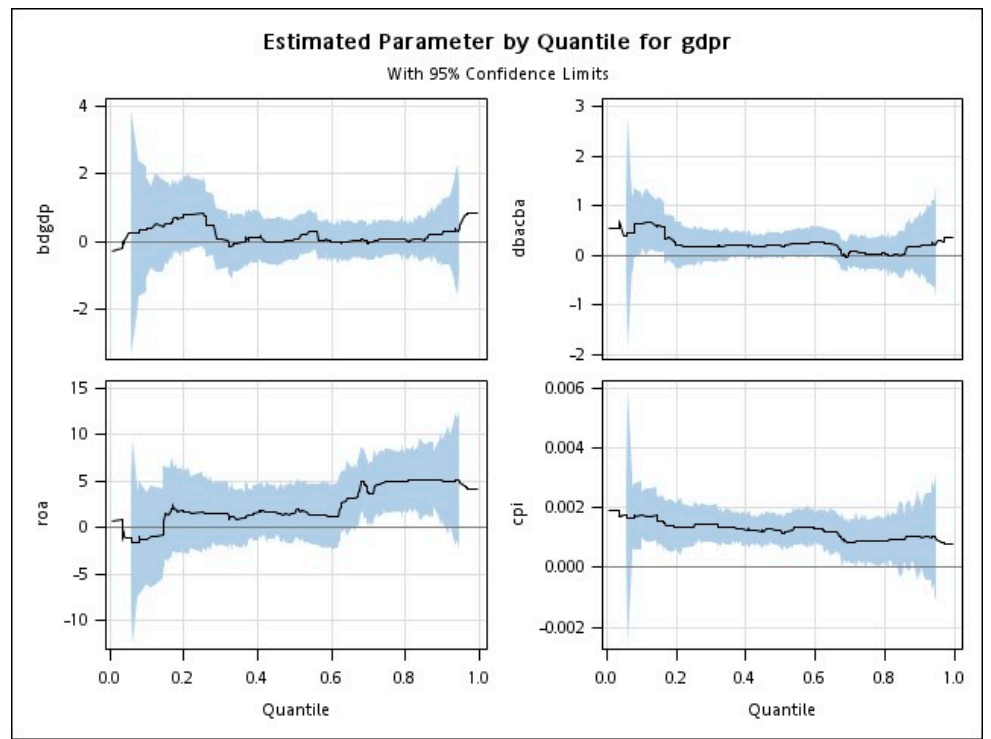

Figure 1. Quantile estimates of four dependent variables.

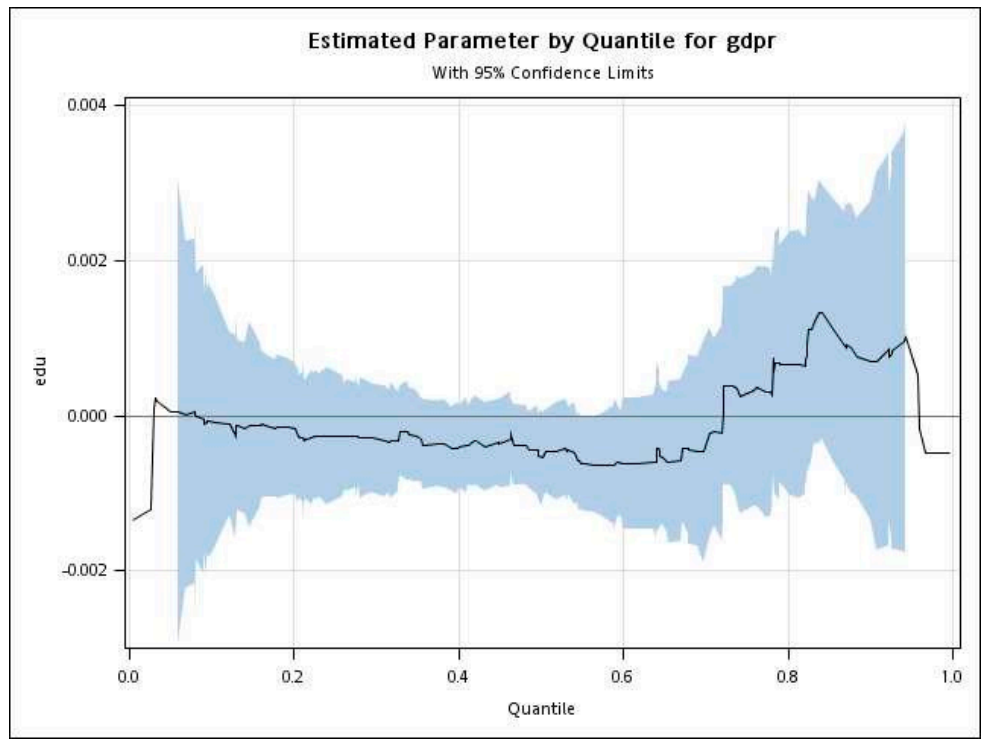

Figure 2. Quantile plot for education level with 95\% confidence interval.

\section{Conclusions}

Most research has only postulated that the development of financial intermediaries causes economic growth. However, previous literature does not investigate that with countries at different levels of economic development, financial development can asymmetrically affect economic growth. Employing QR, this study reveals that a difference does exist between high-income countries and low-income countries. Specifically, financial sector development is the main driver of economic growth for high-income countries only, not for low-income countries. Therefore, low-income countries should not develop financial intermediaries indiscriminately in the pursuit of economic expansion. Overall, our empirical findings have important policy implications for policy makers who are especially concerned about the achievement of countries' sustainable economic growth. Finally, we note the limitations of the dataset we employed. Possible biases arise from using a dataset that has missing values in the human capital data (i.e., education level) for many countries. Our results thus should be interpreted with caution in this case. 
Author Contributions: Conceptualization, Y.-K.C. and C.-C.Y.; writing-original draft preparation, C.-C.Y.; methodology, Y.-K.C. and C.-C.Y.; software, C.-C.Y.; formal analysis, C.-C.Y.; data curation, C.-C.Y.; writing-review and editing, Y.-K.C.; supervision, C.-C.Y. All authors have read and agreed to the published version of the manuscript.

Funding: This study is funded by the ministry of science and technology (MOST) program (MOST 108-2410-H-033-015).

Conflicts of Interest: The authors declare no conflict of interest.

\section{References}

1. Romer, P.M. Endogenous technological change. J. Political Econ. 1990, 98, 71-102. [CrossRef]

2. Koenker, R.; Gilbert, B. Regression quantiles. Econometrica 1978, 46, 211-244. [CrossRef]

3. Fu, Z.; Xi, D.; Xu, J. Bank competition, financial development, and income inequality. Contemp. Econ. Policy 2020. forthcoming.

4. Levine, R.; Beck, T.; Loayza, N. Financial intermediation and growth: Causality and causes. J. Monet. Econ. 2000, 46, 31-77. [CrossRef]

5. Odedokun, M.O. Alternative econometric approaches for analysing the role of the financial sector in economic growth: Time-series evidence from LDCs. J. Dev. Econ. 1996, 50, 119-146. [CrossRef]

6. Cheng, S.Y.; Hou, H. Do non-intermediation services tell us more in the finance-growth nexus? Causality evidence from eight OECD countries. Appl. Econ. 2020, 52, 756-768.

7. Levine, R. Stock markets, growth, and tax policy. J. Financ. 1991, 46, 1445-1465. [CrossRef]

8. Mhadhbi, K.; Terzi, C.; Bouchrika, A. Banking sector development and economic growth in developing countries: A bootstrap panel Granger causality analysis. Empir. Econ. 2020, 58, 2817-2836. [CrossRef]

9. Beck, T.; Demirgüç-Kunt, A.; Laeven, L.; Levine, R. Finance, firm size, and growth. J. Money Credit Bank. 2008, 40, 1379-1405. [CrossRef]

10. Demirgüç-Kunt, A.; Levine, R. Stock market development and financial Intermediaries: Stylized facts. World Bank Econ. Rev. 1996, 10, 291-321. [CrossRef]

11. Bencivenga, V.R.; Smith, B.D. Economic development and financial depth in a model with costly financial intermediation. Res. Econ. 1998, 52, 363-386. [CrossRef]

12. Greenwood, J.; Smith, B.D. Financial markets in development, and the development of financial markets. J. Econ. Dyn. Control 1997, 21, 145-181. [CrossRef]

13. Jones, C.I.; Kim, J. A Schumpeterian model of top income inequality. J. Political Econ. 2018, 126, $1785-1826$. [CrossRef]

14. Aghion, P.; Akcigit, U.; Bergeaud, A.; Blundell, R.; Hemous, D. Innovation and top income inequality. Rev. Econ. Stud. 2019, 86, 1-45. [CrossRef]

15. Goodfriend, M.; McCallum, B.T. Banking and interest rates in monetary policy analysis: A quantitative exploration. J. Monet. Econ. 2007, 54, 1480-1507. [CrossRef]

16. Mello, M.; Perrelli, R. Growth equations: A quantile regression exploration. Q. Rev. Econ. Financ. 2003, 43, 643-667. [CrossRef]

17. Baldwin, R.E.; Forslid, R. The core-periphery model and endogenous growth: Stabilizing and destabilizing intergration. Economica 2000, 67, 307-324. [CrossRef]

18. Beck, T.; Demirgüç-Kunt, A.; Levine, R. Financial Institutions and Markets across Countries and over Time-Data and Analysis; Policy Research Working Paper No. 4943; World Bank: Washington, DC, USA, 2009.

19. Beck, T.; Levine, R.; Loayza, N. Finance and the sources of growth. J. Financ. Econ. 2000, 58, 261-300. [CrossRef]

20. Beck, T.; Demirgüç-Kunt, A.; Levine, R. Finance, inequality and the poor. J. Econ. Growth 2007, 12, $27-49$. [CrossRef]

(C) 2020 by the authors. Licensee MDPI, Basel, Switzerland. This article is an open access article distributed under the terms and conditions of the Creative Commons Attribution (CC BY) license (http://creativecommons.org/licenses/by/4.0/). 